\title{
BMJ Open Factors determining intention to leave among physicians in tertiary hospitals in China: a national cross-sectional study
}

\author{
Chunyu Zhang, ${ }^{\oplus 1,2}$ Linlin $\mathrm{Hu}^{2}{ }^{2}$ Jing Ma, ${ }^{3}$ Shichao $\mathrm{Wu},{ }^{2}$ Jing Guo, ${ }^{2}$ Yuanli $\mathrm{Liu}^{2}$
}

To cite: Zhang C, Hu L, Ma J, et al. Factors determining intention to leave among physicians in tertiary hospitals in China: a national crosssectional study. BMJ Open 2019;9:e023756. doi:10.1136/ bmjopen-2018-023756

- Prepublication history for this paper is available online. To view these files, please visit the journal online (http://dx.doi. org/10.1136/bmjopen-2018023756).

Received 24 April 2018 Revised 24 December 2018 Accepted 31 December 2018

A) Check for updates

(c) Author(s) (or their employer(s)) 2019. Re-use permitted under CC BY-NC. No commercial re-use. See rights and permissions. Published by BMJ.

${ }^{1}$ China-Japan Friendship Hospital, Beijing, China ${ }^{2}$ School of Public Health, Chinese Academy of Medical Sciences and Pecking Union Medical College, Beijing, China ${ }^{3}$ Department of Population Medicine, Harvard Medical School, Harvard Pilgrim Health Care Institute, Boston, Massachusetts, USA

Correspondence to

Yuanli Liu;

liuyuanli_pumc@163.com

\section{ABSTRACT}

Objective The reasons that physicians leave the institutions have not been extensively studied. We aimed to evaluate these reasons, which include the desire to work at another hospital or the intention to make a career change, among physicians in tertiary hospitals in China and explore the associations between the individual-level and organizational-level factors related to these two reasons for leaving.

Methods We conducted a national survey of 136 tertiary hospitals across all 31 provinces in China between December 2017 and January 2018. A total of 20785 physicians were selected to self-report on the two evaluated reasons related to physicians' intent to leave. A univariate analysis and multilevel regression model were applied to evaluate the factors associated with intention to leave.

Result In all, $10.4 \%$ of the participating physicians had thought about working at another hospital, and 20.5\% intended to leave to make a career change. At the hospital level, the government subsidy per bed $(\mathrm{OR}=0.88,95 \% \mathrm{Cl}$ : 0.86 to 0.98 and $\mathrm{OR}=0.91,95 \% \mathrm{Cl}: 0.90$ to 0.99$)$, personnel funding per capita (OR=0.86, $95 \% \mathrm{Cl}: 0.76$ to 0.96 and $\mathrm{OR}=0.80,95 \% \mathrm{Cl}: 0.73$ to 0.88$)$ and the number of physicians per bed $(\mathrm{OR}=0.83,95 \% \mathrm{Cl}: 0.81$ to 0.86 and $\mathrm{OR}=0.89,95 \% \mathrm{Cl}$ 0.81 to 0.92 ) were negatively associated, while the number of hospital-level medical disputes $(\mathrm{OR}=1.04,95 \% \mathrm{Cl}: 1.03$ to 1.05 and $\mathrm{OR}=1.06,95 \% \mathrm{Cl}: 1.01$ to 1.11 ) was positively associated with both reasons for leaving. At the individual level, income ( $\mathrm{OR}=0.74,95 \% \mathrm{Cl}$ : 0.71 to 0.79 and $\mathrm{OR}=0.88$, $95 \% \mathrm{Cl}: 0.83$ to 0.92$)$ and job satisfaction $(\mathrm{OR}=0.18,95 \% \mathrm{Cl}$ : 0.17 to 0.20 and $\mathrm{OR}=0.16,95 \% \mathrm{Cl}: 0.15$ to 0.18 ) acted as preventive factors against both reasons for leaving, while work hours per week $(\mathrm{OR}=1.11,95 \% \mathrm{Cl}: 1.06$ to 1.17 and $\mathrm{OR}=1.23$, $95 \% \mathrm{Cl}: 1.19$ to 1.28$)$ and medical dispute $(\mathrm{OR}=1.49$,

$95 \% \mathrm{Cl}: 1.35$ to 1.65 and $\mathrm{OR}=1.77,95 \% \mathrm{Cl}: 1.64$ to 1.91 ) acted as promotive factors.

Conclusions Although the intention to leave is not prevalent among physicians in tertiary hospitals in China, providing more organisational support and a better occupational environment may promote retention among physicians.

\section{INTRODUCTION}

Physician shortages have become a common issue worldwide. Kirch and Petelle predicted that the USA will face a shortage of between 40800 and 104900 physicians by $2030 .{ }^{1}$ China is also experiencing a chronic shortage of
Strengths and limitations of this study

The large sample size (20785 physicians) across 31 provinces offers a certain representativeness.

- We studied two reasons for intending to leave: leaving for another hospital and leaving for another career.

- Multilevel analysis was applied to examine the associations between hospital-level and physician-level factors and leaving intention.

- The main limitation of the study was that we were unable to determine the direction of causality due to the cross-sectional nature of the survey.

physicians. For example, Lien et al reported that the proportion of physicians aged 25-34 years had decreased from $31.3 \%$ to $22.6 \%$, while that of physicians aged more than 60 years had increased from $2.5 \%$ to $11.6 \%$ in the most recent 10 years. ${ }^{2}$ The departure of physicians from jobs is one of the main reasons for this shortage. Physicians leaving jobs is significantly associated with decreases in productivity and in access to healthcare. ${ }^{34}$ These vacancies must be filled, and time is wasted in recruiting and training new physicians. The training cycle is longer and more expensive for physicians than for other occupations. In developed countries, such as the USA, physicians usually have a doctorate degree. In addition to the long period of study in medical school, additional years in postgraduate resident training are required for a physician to be qualified. Retaining physicians has become an important issue for hospital managers.

Researchers agree that it is important to study physicians' intention to leave because it may allow leaving behaviour to be predicted. Degen reviewed 17 studies from 5 countries including the UK, Germany, the USA, France and Finland and found that the physicians' leaving intention ranged from $11.8 \%$ to $22 \% .^{5}$ In a study performed in Taiwan, Tsai et al found that $14.5 \%$ of physicians reported 
a strong intention to leave their current hospital. ${ }^{6}$ In China, Haiqing et al investigated 111 physicians working in secondary hospitals in China and found that $41.0 \%$ of them reported that they intended to leave. ${ }^{7}$ As many as $40 \%-50 \%$ of village doctors were found to have intentions to leave their current hospital. ${ }^{8-10}$ However, national data, especially for Chinese physicians, are limited.

In China, the government advocated for 'initial diagnosis at the primary level', and has made great efforts to invest in grassroots medical institutions and promote standardised training for general practitioners since the beginning of health system reform in 2009. However, the primary healthcare system is still faced with equipment obsolescence and shortages of resources and personnel due to financial limitations. ${ }^{11}$ As a result, the general public still lacks trust in primary healthcare institutions, and tertiary hospitals are overcrowded for even minor problems. ${ }^{12-14}$ A total of $48 \%$ of patients were treated in tertiary hospitals in 2015, growing from only $28.6 \%$ in $2005 .{ }^{15}$ Moreover, the population is rapidly ageing. The number of individuals over 65 years old increased $44.0 \%$, from 104 million in 2006 to 150 million in $2016 .{ }^{16}$ Tertiary hospitals, which play the role of local medical centres, are faced with the substantial challenges associated with treating the complicated diseases caused by ageing. ${ }^{17}$ Chinese physicians in tertiary hospitals are therefore burdened with a heavier workload and more responsibility than specialists in other countries.

Considering that tertiary hospitals undertake almost half of all clinical work in China, that research about leaving intention has been conducted in Western countries or rural China and that little is known about Chinese tertiary hospitals, more attention should be focused on physicians' intention to leave in tertiary hospitals. Furthermore, the intention to leave the current hospital should be specifically addressed with regard for whether the physician is moving between hospitals or between occupations: past studies have seldom considered this point.

Therefore, the purpose of this study is to investigate the intention to leave, including moving to another hospital and changing careers, among physicians in tertiary hospitals in China and to explore the factors that may affect the intention to leave at both the individual and organisation levels.

\section{METHODS}

\section{Study participants}

A national cross-sectional survey was conducted between December 2017 and January 2018. Participants were selected using a multistage sampling method. During the first stage of sampling (hospital level), one provincial general hospital, one provincial traditional Chinese medicine (TCM) hospital and one maternal and child (MC) hospital were selected based on convenience in each of the 31 provinces in China. We also included 43 national health and family planning commission-affiliated hospitals, including 25 general hospitals, $3 \mathrm{MC}$ hospitals and 15 specialty hospitals. The second sampling stage targeted physicians who had worked for more than 1 year in the previously sampled hospitals. Those who had been absent from clinical work for more than 6 months were excluded. We assumed that the proportion of physicians who intended to leave was $25 \%$ based on the results of pilot tests, and we therefore set the relative error ((measured value-true value)/truevalue) and significance level at 0.3 and 0.05 , respectively. We planned for a minimum sample size of 130 physicians at each hospital. The human resources department of each sampled hospital provided a list of all their physicians, and we proportionally selected 150 physicians in three categories (junior, middle and senior) based on the actual ratio of physicians in each of the above professional title categories. Ultimately, 20785 physicians from 136 tertiary hospitals completed the questionnaire. The response rate was $95.5 \%$.

\section{Design}

We implemented a self-administered questionnaire instrument on a smartphone platform (WeChat V.6.5, Tencent). Physicians were required to use their own cell phones to complete the questionnaire. All answers were sent directly and anonymously via the internet to a centralised account to assure confidentiality. A 5-point Likert scale was used to score the answers to the leaving intention questions. Physicians were invited to consider the following statements-'I intend to leave my current hospital for another one in the near future' and 'I intend to leave my current career in the near future'and to rate their perception of each as 'strongly agree', 'agree', 'neither agree nor disagree', 'disagree' or 'strongly disagree'. In addition, the physician questionnaire collected information on physician characteristics (including age, gender, educational background, professional title, management position and specialty), weekly work hours, income (including compensation from the hospital and any grey income) and job satisfaction. Job satisfaction was rated by 'I am satisfied with my current job as a whole' with the response captured on a 5-point Likert scale. With the help of local authorities, the hospital-level variables were exported from hospital information systems and sent to a designated email address. The information collected in the hospital questionnaires was related to hospital type, region, the number of beds, the number of patients and physicians, government subsidies, personnel funding (including salary, bonus, welfare and insurance) and hospital-level medical disputes. To compare the distribution between the sample and the population and determine whether the participating physicians were representative, the sampled hospitals provided the total number of physicians in every professional title. Trained surveyors were assigned to every sampled hospital to help the physicians and hospitals complete the questionnaire. All survey questions were mandatory to complete the survey. 


\section{Statistical analysis}

Continuous measures with a normal distribution are presented as the mean $\pm \mathrm{SD}$. Those with a non-normal distribution are presented as the median (range). Categorical variables are presented as percentages. $\chi^{2}$ tests were performed to compare the intention to leave among subgroups. Associations between intention to leave to change hospitals or to start a new career were estimated using multilevel logistic regression models with a binomial distribution assumption and a logit link. We defined 'strongly agree' and 'agree' as a positive answer (1=yes); 'neither agree nor disagree', 'disagree' and 'strongly disagree' were defined as a negative answer $(0=$ no). In each model, government subsidy per bed, personnel funding per capita, physicians per bed, medical disputes, the number of patients, hospital type and region were included as hospital-level independent variables, while physician gender, age, professional title, management position, weekly work hours, monthly income, specialty, job satisfaction and medical dispute experience were included as independent individual-level variables. The effect of each variable is expressed as an OR with a 95\% CI. All analyses were performed using the SAS V.9.4 software package (SAS Institute). All tests for statistical significance were two sided, and the significance level was set as $\alpha=0.05$.

\section{Patient and public involvement statement}

There is no patient or public participation in this study.

\section{RESULTS}

\section{Characteristics of participating physicians and hospitals}

In table 1, we present the descriptive characteristics of the participating physicians. The participating physicians were distributed equally among junior, middle and senior professional titles, and this distribution was close to the actual distribution. Of the 20785 participating physicians, $43.6 \%$ were male and $56.4 \%$ were female. The mean age was $36.88 \pm 8.22$ years old, and $72.2 \%$ were between 30 and 49 years old. Most of the responding physicians $(73.3 \%)$ reported feeling overworked, and the average weekly work load was 50 (range, 7-120) hours. The median monthly income was 9000 (range, 2000-27 000) $¥$. A total of $34.8 \%$ of the responding physicians had encountered a medical dispute in the last year, and of these, $54.1 \%$ said they experienced physical or verbal violence from patients.

In table 2, we present the data obtained from the sampled hospitals. From the 136 hospitals, the percentages that were general hospitals, TCM hospitals, MC hospitals and specialty hospitals were $41.9 \%, 22.8 \%$, $22.1 \%$ and $13.2 \%$, respectively; $41.2 \%$ of the sampled hospitals were located in Eastern China, 27.2\% in Central China and $31.6 \%$ in Western China. Most of the sampled general hospitals $(61.4 \%)$ had more than 2000 beds, and most of the sampled specialty hospitals $(55.6 \%)$ had fewer than 500 beds. In 2017, the average subsidy received from the government was 82.52 (range, 0-391.84) million $¥$, and the proportion of total hospital income represented by government subsidies was 0.05 (range, 0.01-0.50). Personnel funding provided 440 million (range, 380-26 $280) ¥$, and the proportion of total hospital income represented by personnel funding was 0.33 (range, $0.03-0.63)$. The median for medical disputes was 33 per hospital (range, 0-754) in 2017. Meanwhile, $66.1 \%$ of the responding physicians agreed that their hospitals had adopted actions aimed at preventing medical disputes, and $64.8 \%$ of those physicians agreed that the security staff at their institution could respond quickly when violence occurred.

\section{Physician intention to leave}

Two questions were used to evaluate physician intention to leave. With regard to the first question, 'I intend to leave my current hospital for another one in the near future', $10.4 \%$ of the surveyed physicians responded positively. To the second statement, 'I intend to leave my current career in the near future', $20.5 \%$ of the surveyed physicians responded positively.

From table 3, intention to leave is shown to have an inverted U-type distribution when displayed by age. The proportions of physicians changing hospitals and making a career change were higher in the middle-age group than in the younger and older groups. Physicians in MC hospitals reported the highest likelihood of intention to leave for another hospital or to change a career $(12.1 \%, 22.8 \%)$, followed by those in general hospitals $(11.1 \%, 21.3 \%)$. Among practitioners in all specialties, paediatricians were the most likely to intend to leave their current hospital for another $(14.4 \%)$ or to change careers $(30.4 \%)$. The likelihoods of intention to leave for a new hospital or a new career were highest in Western China $(12.4 \%, 24.3 \%)$ and lowest in Eastern China $(8.4 \%, 15.8 \%)$. Physicians who reported dissatisfaction with their job had a higher likelihood of intending to leave for both reasons $(27.6 \%, 50.2 \%)$ than was found in those who felt satisfied $(5.5 \%, 12.1 \%)$. The majority $(45.9 \%)$ chose 'the income distribution policy' as the top factor influencing job satisfaction, followed by 'work environment safety' (25.9\%).

\section{Hospital-level and physician-level factors associated with intention to leave}

The associations between intention to leave and factors at the physician and hospital levels are shown in table 4, which displays data resulting from a multilevel logistic regression analysis. The hospital type, region, and number of physicians and the physician's gender, age, management position, professional title and specialty were controlled as confounders.

At the hospital level, government subsidies per bed $(\mathrm{OR}=0.88,95 \%$ CI: 0.86 to 0.98 and $\mathrm{OR}=0.91,95 \%$ CI: 0.90 to 0.99 ), personnel funding per capita as provided by the hospital ( $\mathrm{OR}=0.86,95 \%$ CI: 0.76 to 0.96 and $\mathrm{OR}=0.80$, 95\% CI: 0.73 to 0.88 ) and the number of physicians 
Table 1 Characteristics of the responding physicians

\begin{tabular}{|c|c|c|c|}
\hline Characteristics & Overall (\%) & Male (\%) & Female (\%) \\
\hline Total & 20785 & 9055 (43.6) & $11730(56.4)$ \\
\hline \multicolumn{4}{|l|}{ Age (years) } \\
\hline$<30$ & $3711(17.9)$ & $1295(14.3)$ & $2416(20.6)$ \\
\hline $30-39$ & $10382(49.9)$ & $4539(50.1)$ & $5843(49.8)$ \\
\hline $40-49$ & $4633(22.3)$ & $2226(24.6)$ & $2407(20.5)$ \\
\hline$\geq 50$ & $2059(9.9)$ & $995(11.0)$ & $1064(9.1)$ \\
\hline \multicolumn{4}{|l|}{ Educational background } \\
\hline Bachelor's degree and below & $5952(28.6)$ & $2475(27.3)$ & $3477(29.6)$ \\
\hline Master's & $9711(46.7)$ & $391(43.3)$ & $5792(49.4)$ \\
\hline Doctorate & $5122(24.6)$ & $2661(29.4)$ & $2461(21.0)$ \\
\hline \multicolumn{4}{|l|}{ Professional title } \\
\hline Junior & 6768 (32.6) & $2599(28.7)$ & $4169(35.5)$ \\
\hline Middle & $7483(36.0)$ & $3269(36.1)$ & $4214(35.9)$ \\
\hline Senior & $6534(31.4)$ & 3187 (35.2) & 3347 (28.5) \\
\hline \multicolumn{4}{|l|}{ Management position } \\
\hline Yes & 2568 (12.4) & $1382(15.3)$ & $1186(10.1)$ \\
\hline No & $18217(87.6)$ & $7673(84.7)$ & $10544(89.9)$ \\
\hline \multicolumn{4}{|l|}{ Specialty } \\
\hline Internal medicine & $4878(23.5)$ & $1881(20.8)$ & $2997(25.5)$ \\
\hline Surgery & $3151(15.2)$ & $2716(30.0)$ & $435(3.7)$ \\
\hline Obstetrics & $2939(14.1)$ & $401(4.4)$ & $2538(21.6)$ \\
\hline Paediatrics & $1762(8.5)$ & $433(4.8)$ & $1329(11.3)$ \\
\hline Emergency medicine & $696(3.3)$ & $387(4.3)$ & $309(2.6)$ \\
\hline Traditional Chinese medicine & $724(3.5)$ & $316(3.5)$ & $408(3.5)$ \\
\hline Otolaryngology & $433(2.1)$ & $200(2.2)$ & $233(2.0)$ \\
\hline Anaesthesiology & $1037(5.0)$ & $433(4.8)$ & $604(5.1)$ \\
\hline Ophthalmology & $706(3.4)$ & $226(2.5)$ & $480(4.1)$ \\
\hline Stomatology & $986(4.7)$ & $451(5.0)$ & $535(4.6)$ \\
\hline Dermatology & $441(2.1)$ & $151(1.7)$ & $290(2.5)$ \\
\hline Other & $3032(14.6)$ & $1460(16.1)$ & $1572(13.4)$ \\
\hline \multicolumn{4}{|l|}{ Monthly income (¥) } \\
\hline$<5000$ & 2909 (14.0) & $1130(12.5)$ & 1779 (15.2) \\
\hline $5000 \leq 10000$ & $9781(47.1)$ & $4021(44.4)$ & $5760(49.1)$ \\
\hline $10000 \leq 15000$ & $5513(26.5)$ & $2620(28.9)$ & $2893(24.7)$ \\
\hline $15000 \leq 20000$ & $1766(8.5)$ & $847(9.4)$ & $919(7.8)$ \\
\hline$\geq 20000$ & $816(3.9)$ & $437(4.8)$ & 379 (3.2) \\
\hline \multicolumn{4}{|l|}{ Weekly work hours } \\
\hline$\leq 40$ & $5556(26.7)$ & $2247(24.8)$ & $3309(28.2)$ \\
\hline $40 \leq 50$ & $6745(32.5)$ & $2864(31.6)$ & 3881 (33.1) \\
\hline $50 \leq 60$ & 4595 (22.1) & $2097(23.2)$ & 2498 (21.3) \\
\hline$>60$ & 3889 (18.7) & 1847 (20.4) & $2042(17.4)$ \\
\hline
\end{tabular}

per bed $(\mathrm{OR}=0.83,95 \% \mathrm{CI}: 0.81$ to 0.86 and $\mathrm{OR}=0.89$, 95\% CI: 0.81 to 0.92 ) were negatively associated with the desire to work at another hospital and the intention to make a career change. As the number of medical disputes increased to some extent (ie, 50), the estimated number of positive responses to the two reasons for intending to leave also increased ( $\mathrm{OR}=1.04,95 \% \mathrm{CI}: 1.03$ to 1.05 and $\mathrm{OR}=1.06,95 \% \mathrm{CI}: 1.01$ to 1.11 , respectively). 
Table 2 Characteristics of the sampled hospitals

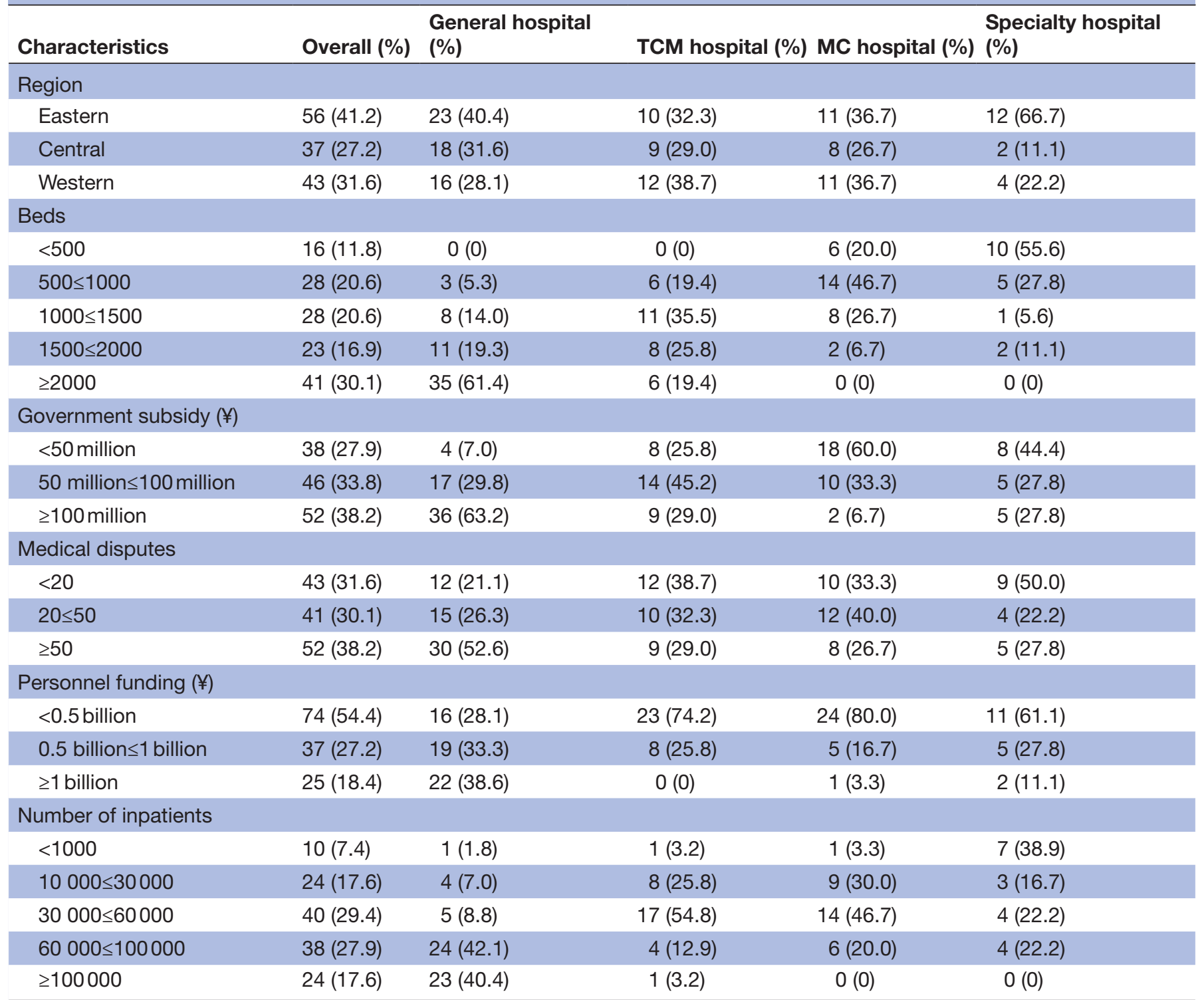

MC hospital, maternal and child hospital; TCM hospital, traditional Chinese medical hospital.

At the physician level, overtime work was associated with a higher likelihood of physicians intending to change hospitals or to leave their current career $(\mathrm{OR}=1.11$, 95\% CI: 1.06 to 1.17 and $\mathrm{OR}=1.23,95 \% \mathrm{CI}: 1.19$ to 1.28 , respectively). Income ( $\mathrm{OR}=0.74,95 \% \mathrm{CI}: 0.71$ to 0.79 and $\mathrm{OR}=0.88,95 \% \mathrm{CI}: 0.83$ to 0.92 , respectively) was negatively associated with both reasons for intending to leave. Physicians who were satisfied with their job were less likely to change hospitals $(\mathrm{OR}=0.18,95 \% \mathrm{CI}: 0.17$ to 0.20$)$ or leave their current career ( $\mathrm{OR}=0.16,95 \% \mathrm{CI}$ : 0.15 to 0.18$)$ than those who gave a negative answer to job satisfaction. Physicians who had experienced a medical dispute during the last year were more likely to change hospitals $(\mathrm{OR}=1.49,95 \% \mathrm{CI}: 1.35$ to 1.65$)$ or to leave their current career $(\mathrm{OR}=1.77,95 \% \mathrm{CI}: 1.64$ to 1.91$)$ than those who had not encountered a medical dispute.

\section{DISCUSSION}

In this study, we conducted a national survey to analyse and examine the factors associated with intention to leave among physicians in Chinese tertiary hospitals. We found that $10.4 \%$ of the participating physicians thought about changing hospitals, and $20.5 \%$ of them intended to change careers. Through multilevel logistic regression models, we found that the government subsidy per bed, personnel funding per capita, the number of physicians per bed and the number of hospital medical disputes significantly affected physician intention to leave. Additionally, at the physician level, we found that income and job satisfaction were negatively associated, while weekly work hours and experience with medical disputes were positively associated with the two reasons for intending to leave. To improve physician retention, it is necessary to 
Open access

Table 3 The intention to leave among subgroups

\section{Characteristics}

Total

Age (years)

$<30$
$30-39$
$40-49$
$\geq 50$
Gender
Male

Male

Female

Specialty

Internal medicine

Surgery

Obstetrics

Paediatrics

Emergency medicine

Traditional Chinese medicine

Otolaryngology

Anaesthesiology

Ophthalmology

Stomatology

Dermatology

Other

Monthly income $(¥)$

$<5000$

$5000 \leq 10000$

$10000 \leq 15000$

$15000 \leq 20000$

$\geq 20000$

Weekly work hours

$\leq 40$

$40 \leq 50$

$50 \leq 60$

$>60$

Job satisfaction

Negative perception

Positive perception

Region

Eastern

Hospital type

General hospital

TCM hospital

MC hospital

Specialty hospital
Total number

20785

3711

10382

4633

2059

9055

11730

4878

3151

2939

1762

696

724

433

1037

706

986

441

3032

2909

9781

5513

1766

816

5556

6745

4595

3889

4623

16162

8028

5384

7373

8754

5214

4218

2599

Changed hospital (\%)
$2171(10.4)$

$P$ value

$<0.001$

$341(9.2)$

1179 (11.3)

$521(11.2)$

139 (6.8)

1075 (11.9)

$1096(9.3)$

479 (9.8)

346 (11.0)

302 (10.3)

254 (14.4)

83 (11.9)

84 (11.6)

50 (11.5)

79 (7.6)

61 (8.6)

128 (13.0)

34 (7.7)

271 (8.9)

394 (13.5)

1071 (10.9)

485 (8.8)

154 (8.7)

67 (8.2)

420 (7.6)

619 (9.2)

569 (12.4)

563 (14.5)

1276 (27.6)

895 (5.5)

675 (8.4)

579 (10.8)

917 (12.4)

973 (11.1)

441 (8.5)

512 (12.1)

245 (9.4)

$<0.001$

$<0.001$

$<0.001$

$<0.001$

$<0.001$

$<0.001$

$<0.001$

Changed care
$4271(20.5)$

$671(18.1)$
$2298(22.1)$
$970(20.9)$
$332(16.1)$

1873 (20.7)

2398 (20.4)

$<0.001$

1069 (21.9)

635 (20.2)

594 (20.2)

536 (30.4)

196 (28.2)

$156(21.5)$

75 (17.3)

104 (10.0)

110 (15.6)

184 (18.7)

71 (16.1)

541 (17.8)

$<0.001$

714 (24.5)

2221 (22.7)

967 (17.5)

272 (15.4)

97 (11.9)

780 (14.0)

$1182(17.5)$

1130 (24.6)

1179 (30.3)

$<0.001$

2319 (50.2)

1952 (12.1)

$<0.001$

1267 (15.8)

1216 (22.6)

1788 (24.3)

$<0.001$

1863 (21.3)

1005 (19.3)

963 (22.8)

440 (16.9)

MC hospital, maternal and child hospital; TCM hospital, traditional Chinese medical hospital. 
Table 4 Hospital-level and physician-level factors associated with intention to leave

\begin{tabular}{|c|c|c|}
\hline Factors & Model 1 & Model 2 \\
\hline \multicolumn{3}{|l|}{ Hospital-level factors } \\
\hline $\begin{array}{l}\text { Government subsidy per } \\
\text { bed ( } ¥)\end{array}$ & $0.88(0.86,0.98)^{\star}$ & $0.91(0.90,0.99)^{\star}$ \\
\hline \multicolumn{3}{|l|}{$1=`<50000 ’$} \\
\hline \multicolumn{3}{|l|}{$2=` 50000 \leq 100000 ’$} \\
\hline \multicolumn{3}{|l|}{$3==^{\prime} \geq 100000^{\prime}$} \\
\hline $\begin{array}{l}\text { Personnel funding per } \\
\text { capita ( } ¥)\end{array}$ & $0.86(0.76,0.96)^{\star}$ & $0.80(0.73,0.88)^{\star}$ \\
\hline \multicolumn{3}{|l|}{$1=`<200000 ’$} \\
\hline \multicolumn{3}{|l|}{$2=‘ 200000 \leq 300000 ’$} \\
\hline \multicolumn{3}{|l|}{$3={ }^{\prime} \geq 300000^{\prime}$} \\
\hline $\begin{array}{l}\text { Number of physician per } \\
\text { bed }\end{array}$ & $0.83(0.81,0.86)^{\star}$ & $0.89(0.81,0.92)^{\star}$ \\
\hline \multicolumn{3}{|l|}{$1={ }^{\prime}<0.3^{\prime}$} \\
\hline \multicolumn{3}{|l|}{$2={ }^{\prime} 0.3 \leq 0.5^{\prime}$} \\
\hline \multicolumn{3}{|l|}{$3={ }^{\prime} \geq 0.5 ’$} \\
\hline Medical disputes & $1.04(1.03,1.05)^{\star}$ & $1.06(1.01,1.11)^{\star}$ \\
\hline \multicolumn{3}{|l|}{$1={ }^{\prime}<20^{\prime}$} \\
\hline \multicolumn{3}{|l|}{$2=‘ 20 \leq 50 ’$} \\
\hline \multicolumn{3}{|l|}{$3=` \geq 50 ’$} \\
\hline \multicolumn{3}{|l|}{ Physician-level factors } \\
\hline Weekly work hours & $1.11(1.06,1.17)^{\star}$ & $1.23(1.19,1.28)^{\star}$ \\
\hline \multicolumn{3}{|l|}{$1=` \leq 40 ’$} \\
\hline \multicolumn{3}{|l|}{$2=` 40 \leq 50 ’$} \\
\hline \multicolumn{3}{|l|}{$3=` 50 \leq 60 ’$} \\
\hline \multicolumn{3}{|l|}{$4=`>60 ’$} \\
\hline Monthly income (¥) & $0.74(0.71,0.79)^{\star}$ & $0.88(0.83,0.92)^{\star}$ \\
\hline \multicolumn{3}{|l|}{$1=`<5000 ’$} \\
\hline \multicolumn{3}{|l|}{$2=` 5000 \leq 10000 ’$} \\
\hline \multicolumn{3}{|l|}{$3=‘ 10000 \leq 15000 ’$} \\
\hline \multicolumn{3}{|l|}{$4=‘ 15000 \leq 20000 ’$} \\
\hline \multicolumn{3}{|l|}{$5=` \geq 20000^{\prime}$} \\
\hline Job satisfaction & $0.18(0.17,0.20)^{\star}$ & $0.16(0.15,0.18)^{\star}$ \\
\hline \multicolumn{3}{|l|}{$0=$ 'Negative perception' } \\
\hline \multicolumn{3}{|l|}{ 1=‘Positive perception’ } \\
\hline $\begin{array}{l}\text { Encountered medical } \\
\text { disputes }\end{array}$ & $1.49(1.35,1.65)^{\star}$ & $1.77(1.64,1.91)^{\star}$ \\
\hline \multicolumn{3}{|l|}{$0={ }^{\prime} \mathrm{No}$ ' } \\
\hline 1='Yes' & & \\
\hline
\end{tabular}

Results are presented as OR and $95 \% \mathrm{Cl}$.

The estimated random effect is 0.296 and 0.249 for model 1 and model 2 , respectively (both $\mathrm{p}<0.01$ ).

Model 1, intention to leave current hospital for another.

Model 2, intention to leave current career.

${ }^{*} \mathrm{p}<0.01$.

discuss those factors associated with the two reasons for intending to leave so that we can provide suggestion to authorities and hospital administrators.

Our analysis of ratings related to the intention to leave produced results similar to those found for developed countries and areas, which range from $11.8 \%$ to $22 \% .^{56}$ Studies have reported that $5 \%-27 \%$ of nurses in China,
Japan and 10 European countries state that they intend to leave their current hospital. ${ }^{18-20}$ The proportion of individuals intending to leave is similar for nurses and for our participating physicians. However, compared with village doctors in China, where approximately $40 \%-50 \%$ reported planning to leave the organisation where they were currently employed, ${ }^{8-10}$ the physicians included in our survey were relatively less likely to intend to leave. Filho and colleagues found that physicians did not intend to leave their hospitals because they desire to work at a prestigious institution. ${ }^{21}$ Our sampled hospitals were all tertiary institutions and top-ranked hospitals in China. Finally, in our study, the proportion of physicians with the intention to leave was lower than that for village doctors in China.

In this report, the hospital-level and physician-level factors that affect a physician's decision to leave his or her current hospital were studied. Some of our findings were interesting. Few studies have characterised whether personnel funding and government subsidies affect physicians' intention to leave. Hence, the results of this study add to this evidence base by providing the first data indicating that receiving financial support from the hospital and the government can prevent physicians from leaving. Personnel funding, which is usually paid in the form of salary, benefits, welfare and insurance, is a predictor of the organisation's financial support to the individuals it employs. As a result, the data obtained in our study demonstrate that physicians working at hospitals providing a higher level of personnel funding per capita are less likely to intend to leave. Because the sampled hospitals were all public hospitals run by the government, government subsidies are an important source of hospital funds. Meanwhile, among types of support from the government such as tax exemption policies, government subsidies provide a measurable index that could represent the support of the government and the importance it places on the hospital. It was found in our study that a higher government subsidy per bed is associated with a lower intention to leave. However, in China, only $4 \%-5.28 \%$ of the gross domestic product is spent on healthcare, whereas this number is $17.4 \%$ in the USA and $8.5 \%$ in Japan. ${ }^{22}$ Because subsidies from the government are small, physicians must make a profit to improve their compensation. The high pressure of making a profit is an obstacle to retaining physicians.

We found that a higher income was associated with a lower likelihood of intending to leave. The average income reported by participating physicians was 9000¥ (1364\$) which is only 1.6 times higher than the national average. Considering the long training period and high risk associated with becoming a physician, this income does not reflect the value that physicians provide. In developed countries, such as the UK and the USA, the income of specialists is usually to 3 to 4 times of the national average income ${ }^{22}$; therefore, the income found in our study was relatively low. Physicians, like everyone, are interested in their income. ${ }^{23-25}$ Hence, the mechanism through which 
physicians are paid and how much they are paid can affect intention to resign.

In line with the results of many previous studies, we found that work hours were independently related with intention to leave. ${ }^{62627}$ The average number of work hours among the participating physicians was 50 per week, which is higher than that for physicians in the USA (49.6 hours per week). ${ }^{28}$ More importantly, $73.3 \%$ of the participating physicians reported working more than 40 hours per week, which is the legal number of work hours per week in China, and $18.7 \%$ worked more than 60 hours per week. The number of work hours is a tangible and actionable factor. By reasonably regulating work hours, we can reduce the possibility that physicians will leave their current hospital. ${ }^{29} 30$ Our study also found that the number of physicians per bed was a preventive factor against the two reasons for leaving. The number of full time employees might need to be increased in tertiary hospitals. Sufficient physicians could lessen a heavy work load and prevent overtime work beyond the regulated work hours.

We found that medical disputes were a significant contributor to physicians' intention to leave. Furthermore, we provide evidence showing that a hospital's total number of medical disputes also affected physician intention to leave. In China, the physician-patient relationship has been characterised as tense, lacking in trust and counterproductive. ${ }^{31-33}$ More than one-third of physicians surveyed in this report had encountered a medical dispute in the last year, and more than half of them reported experiencing physical or verbal violence from patients. Hence, the tense nature of the physicianpatient relationship was confirmed by the results of our study. However, only $66.1 \%$ of the surveyed physicians agreed that their hospital had adopted actions aimed at preventing medical disputes, and only $64.8 \%$ of the participants said that the security staff at their institutions responded as soon as the violence occurred. Considering the unsatisfactory response of the hospital system to medical disputes, we suggest that hospital administrators could improve their responsiveness to retain physicians.

We found that job satisfaction plays a role in physician retention, consistent with former studies. ${ }^{44} 35$ Job satisfaction is a mediator between the workplace and employees' intention to leave. ${ }^{36-39}$ When an organisation or work environment does not achieve employee expectations, employees will feel dissatisfied, which can result in a decision to quit. ${ }^{40}{ }^{41}$ In our study, we asked physicians to identify the main factors affecting their job satisfaction, and most cited the income distribution policy and work environment safety. As a result, fairness in reimbursement and the organisation's quick response to medical violence have been suggested to increase physician satisfaction. ${ }^{42-44}$

Paediatricians had the highest rate of intending to leave in our survey. Compared with general hospitals, TCM hospitals and other specialty hospitals, MC hospitals, which have a higher proportion of paediatricians, also consistently showed a higher likelihood of intending to leave. The Chinese medical doctor association claimed that the shortage of paediatricians is severe, and China is short at least 200000 paediatricians.$^{45}$ Low income and high pressure stemming from the high expectations of children's parents were the main explanation for the paediatrician shortage. ${ }^{46}$ Income and medical disputes were also proven to affect the leaving intention of physicians in our survey. Therefore, attention should be given to measures to improve the income and work environment of paediatricians.

Physicians in Western China reported a higher intention to leave, followed by those in Central and Eastern China. Regions with a better socioeconomic environment attract more physicians. ${ }^{47}$ Western China has a lower economic status and thus suffers from greater human health resource inequality than Central and Eastern China, which have higher economic status. ${ }^{48}$ Perhaps, the physicians in Western China had a higher likelihood of intending to leave because of their poor economic status.

There are important limitations to our study. First, because this was a self-reported survey, we cannot be sure whether intention to leave was under-reported or over-reported. However, the physicians may have been more forthcoming because the survey was anonymous. Meanwhile, physicians may have been cautious about reporting grey income, and so the total compensation could have been underestimated. Second, because this was a cross-sectional study, we were unable to ascertain the directionality of causal relationships between the potential factors and intention to leave, and this should therefore be addressed in future longitudinal studies. Third, in this study, we examined the variables commonly used to explain intention to leave. The associations between individual and organisational factors and intention to leave are complex. Culture, coworkers and other predictors of the doctor-patient relationship were not included in our study. Finally, we lack the information to analyse the different characteristics and reasons behind intention to leave. We will conduct detailed interviews in the near future.

\section{CONCLUSIONS}

In this study, we explore factors that contribute to the intention to leave among physicians in tertiary hospitals in China and demonstrate that there are associations between hospital-level and physician-level factors and two types of intention to leave: the intention to change to a different hospital and the intention to leave the career altogether. Although most of the surveyed physicians reported that they did not intend to leave their current hospital, we found that government subsidy per bed, personnel funding per capita, number of physicians per bed, individual income and job satisfaction were negatively associated with both reasons for leaving, while the total number of medical disputes reported by a hospital, individual experience with medical disputes and weekly work hours were positively related to both reasons for 
leaving. Our findings provide important insights that authorities and hospital administrators should consider when attempting to improve physician retention.

Acknowledgements The authors gratefully acknowledge the health authorities and experts in the 31 provinces who helped coordinate activities at the sample hospitals.

Contributors CZ, LH, JM and YL conceived and designed the study. CZ, SW and JG collected, cleaned and analysed the data. CZ wrote the first draft of the manuscript. $\mathrm{LH}$ and $\mathrm{YL}$ edited the manuscript and provided expert advice based on their medical specialist knowledge. All authors critically read and approved the final manuscript.

Funding This work was supported by a grant from the National Health and Family Planning Commission, P.R. China.

Competing interests None declared.

Patient consent for publication Not required.

Ethics approval This study was approved by the Research Ethics Committee of the Chinese Academy of Medical Science and Peking Union Medical College.

Provenance and peer review Not commissioned; externally peer reviewed.

Data sharing statement The data that support the findings presented in this study are available from the Public Health School of Peking Union Medical College with a few restrictions. The data were used under licence for the current study and so are not publicly available. Data are, however, available from the authors upon reasonable request and with permission from the Authority of Public Health School of Peking Union Medical College.

Open access This is an open access article distributed in accordance with the Creative Commons Attribution Non Commercial (CC BY-NC 4.0) license, which permits others to distribute, remix, adapt, build upon this work non-commercially, and license their derivative works on different terms, provided the original work is properly cited, appropriate credit is given, any changes made indicated, and the use is non-commercial. See: http://creativecommons.org/licenses/by-nc/4.0/.

\section{REFERENCES}

1. Kirch DG, Petelle K. Addressing the physician shortage: the peril of ignoring demography. JAMA 2017;317:194-8.

2. Lien SS, Kosik RO, Fan AP, et al. 10-year trends in the production and attrition of Chinese medical graduates: an analysis of nationwide data. The Lancet 2016;388:S11.

3. Freeborn DK, Hooker RS, Pope CR. Satisfaction and well-being of primary care providers in managed care. Eval Health Prof 2002;25:239-54.

4. Dewa CS, Loong D, Bonato S, et al. How does burnout affect physician productivity? A systematic literature review. BMC Health Serv Res 2014;14:1-10.

5. Degen C, Li J, Angerer P. Physicians' intention to leave direct patient care: an integrative review. Hum Resour Health 2015;13:74.

6. Tsai YH, Huang N, Chien LY, et al. Work hours and turnover intention among hospital physicians in Taiwan: does income matter? BMC Health Serv Res 2016;16:667.

7. Haiqing F, Xiaoxu Z, Shuliang M, et al. Study of country pilot hospital personnal working condition and management strategy. China Hosp Manag 2012;32:12-14

8. Fang P, Liu X, Huang L, et al. Factors that influence the turnover intention of Chinese village doctors based on the investigation results of Xiangyang City in Hubei Province. Int J Equity Health 2014;13:1-9.

9. Wen $T$, Zhang $Y$, Wang $X$, et al. Factors influencing turnover intention among primary care doctors: a cross-sectional study in Chongqing, China. Hum Resour Health 2018;16:10.

10. Zhang $X$, Fang P. Job satisfaction of village doctors during the new healthcare reforms in China. Aust Health Rev 2016;40:225-33.

11. Li H, Liu K, Gu J, et al. The development and impact of primary health care in China from 1949 to 2015: A focused review. Int J Health Plann Manage 2017;32:339-50.

12. Kong $X$, Yang $Y$. The current status and challenges of community general practitioner system building in China. QJM 2015;108:89-91.

13. Jing $L$, Shu Z, Sun $X$, et al. Factors influencing patients' contract choice with general practitioners in Shanghai: a preliminary study. Asia Pac J Public Health 2015;27:77S-85.

14. Hung LM, Rane S, Tsai J, et al. Advancing primary care to promote equitable health: implications for China. Int $J$ Equity Health 2012;11:2-5
15. National Health and Family Planning Commision PRC. China Health and Family Planning Yearbook. Beijing: China Health and Family Planning Commision Yearbook press, 2016.

16. National Bureau of Statistics of China. Chinese statistic year books in 2017. 2017 http://www.stats.gov.cn/tjsj/ndsj/2017/indexch.htm (Accessed 18 Mar 2018).

17. Prince MJ, Wu F, Guo Y, et al. The burden of disease in older people and implications for health policy and practice. Lancet 2015;385:549-62.

18. Leineweber C, Chungkham HS, Lindqvist R, et al. Nurses' practice environment and satisfaction with schedule flexibility is related to intention to leave due to dissatisfaction: A multi-country, multilevel study. Int J Nurs Stud 2016;58:47-58

19. Saijo $Y$, Yoshioka E, Kawanishi Y, et al. Relationships of job demand, job control, and social support on intention to leave and depressive symptoms in Japanese nurses. Ind Health 2016;54:32-41.

20. Zhang LF, You LM, Liu K, et al. The association of Chinese hospital work environment with nurse burnout, job satisfaction, and intention to leave. Nurs Outlook 2014;62:128-37.

21. de Oliveira Vasconcelos Filho P, de Souza MR, Elias PE, et al. Physicians' job satisfaction and motivation in a public academic hospital. Hum Resour Health 2016;14:75.

22. OECD. OECD statistic. http://stats.oecd.org/ (Accessed $18 \mathrm{Mar}$ 2018).

23. Coniglio D, Akroyd D. Factors predicting physician assistant faculty intent to leave. J Physician Assist Educ 2015;26:113-22.

24. Feng D, Su S, Yang Y, et al. Job satisfaction mediates subjective social status and turnover intention among Chinese nurses. Nurs Health Sci 2017;19:388-92.

25. Erus B, Hatipoglu O. Physician payment schemes and physician productivity: analysis of Turkish healthcare reforms. Health Policy 2017;121:553-7.

26. Rabatin J, Williams E, Baier Manwell L, et al. Predictors and outcomes of burnout in primary care physicians. J Prim Care Community Health 2016;7:41-3.

27. Degen C, Li J, Angerer P. Physicians' intention to leave direct patient care: an integrative review. Hum Resour Health 2015;13:74

28. Staiger DO, Auerbach DI, Buerhaus PI. Trends in the work hours of physicians in the United States. JAMA 2010;303:747-53.

29. Lu Y, Hu XM, Huang XL, et al. The relationship between job satisfaction, work stress, work-family conflict, and turnover intention among physicians in Guangdong, China: a cross-sectional study. BMJ Open 2017;7:e014894.

30. Wada K, Arimatsu M, Higashi T, et al. Physician job satisfaction and working conditions in Japan. J Occup Health 2009;51:261-6.

31. Wang Z, Xie Z, Dai J, et al. Physician burnout and its associated factors: a cross-sectional study in Shanghai. J Occup Health 2014; 56:73-83.

32. Tang L, Guan M. Rise of health consumerism in china and its effects on physicians' professional identity and the physician-patient relationship and communication. Health Commun 2018:33.

33. He AJ, Qian J. Explaining medical disputes in Chinese public hospitals: the doctor-patient relationship and its implications for health policy reforms. Health Econ Policy Law 2016;11:359-78.

34. Mohr DC, Burgess JF. Job characteristics and job satisfaction among physicians involved with research in the veterans health administration. Acad Med 2011;86:938-45.

35. Seo HS, Kim H, Hwang SM, et al. Predictors of job satisfaction and burnout among tuberculosis management nurses and physicians. Epidemiol Health 2016;38:e2016008.

36. Muchinsky PM, Morrow PC. A multidisciplinary model of voluntary employee turnover. J Vocat Behav 1980;17:263-90.

37. Zeffane RM. Understanding employee turnover: the need for a contingency approach. Int J Manpow 1994:15:22-37.

38. Quarles R. An examination of promotion opportunities and evaluation criteria as mechanisms for affecting internal auditor commitment, job satisfaction and turnover intentions. J Manage Issues 1994;6:176-94.

39. Iverson RD. An event history analysis of employee turnover: the case of hospital employees in Australia. Human Resource Management Review 1999;9:397-418.

40. Wu D, Wang Y, Lam KF, et al. Health system reforms, violence against doctors and job satisfaction in the medical profession: a cross-sectional survey in Zhejiang Province, Eastern China. BMJ Open 2014;4:e006431.

41. Maslach C, Leiter MP. Early predictors of job burnout and engagement. J Appl Psychol 2008:93:498-512.

42. Girdhari R, Harris A, Fallis G, et al. Family physician satisfaction with two different academic compensation schemes. Fam Med 2013;45:622. 
43. Pathman DE, Konrad TR, Williams ES, et al. Physician job satisfaction, dissatisfaction, and turnover. J Fam Pract 2002;51:593.

44. Tucker JD, Cheng Y, Wong B, et al. Patient-physician mistrust and violence against physicians in Guangdong Province, China: a qualitative study. BMJ Open 2015;5:e008221.

45. Chinese Medical Doctor Association. Paediatricians flee away in China. http://www.cmda.gov.cn/xinwen/redianxinwen/2014-01-24/ 12845.html (Accessed 27 Jun 2018).
46. Hu KJ, Sun ZZ, Rui YJ, et al. Shortage of paediatricians in China. Lancet 2014;383:954.

47. Omrani-Khoo H, Lotfi F, Safari $\mathrm{H}$, et al. Equity in distribution of health care resources; assessment of need and access, using three practical indicators. Iran J Public Health 2013;42:1299-308.

48. Li D, Zhou Z, Si Y, et al. Unequal distribution of health human resource in mainland China: what are the determinants from a comprehensive perspective? Int J Equity Health 2018;17:29. 